\title{
Kinetics and Thermodynamic Studies of Depolymerization of Nylon Waste by Hydrolysis Reaction
}

\author{
D. B. Patil ${ }^{1}$ and S. V. Madhamshettiwar ${ }^{2}$ \\ ${ }^{1}$ Department of Chemistry, Institute of Science, Nagpur 440010, India \\ ${ }^{2}$ Department of Chemistry, Sardar Patel College, Chandrapur 442402, India \\ Correspondence should be addressed to S. V. Madhamshettiwar; svmchd@gmail.com
}

Received 8 September 2014; Revised 18 November 2014; Accepted 18 November 2014; Published 8 December 2014

Academic Editor: Hongxing Dai

Copyright (C) 2014 D. B. Patil and S. V. Madhamshettiwar. This is an open access article distributed under the Creative Commons Attribution License, which permits unrestricted use, distribution, and reproduction in any medium, provided the original work is properly cited.

Depolymerization reaction of nylon waste was carried out by hydrolysis reaction. Yield of depolymerization products was up to $72.20 \%$ for a two-hour reaction time. The products obtained were characterized by melting point and FTIR spectra. The values obtained for dibenzoyl derivative of hexamethylenediamine (DBHMD) agreed with those of the pure substance. Chemical kinetics of this reaction shows that it is a first-order reaction with respect to hexamethylenediamine (HMD) concentration with velocity constant $7.32 \times 10^{-3} \mathrm{~min}^{-1}$. The energy of activation and Arrhenius constant obtained by Arrhenius plot were $87.22 \mathrm{KJg}^{-1}$ and 0.129 , respectively. The other thermodynamic parameters such as enthalpy of activation $\left(\Delta H^{\ddagger}\right)$ and entropy of activation $\left(\Delta S^{\ddagger}\right)$ and free energy of activation were $5975.85 \mathrm{~J}$ and $-270.86 \mathrm{~J} \cdot \mathrm{K}^{-1} \cdot \mathrm{mol}^{-1}$ and $101.59 \mathrm{KJ} \cdot \mathrm{mol}^{-1}$, respectively.

\section{Introduction}

There are many types of industrial waste; among them waste of polymer industry is important because of its resistance to biodegradation. The interest in recycling of nylon waste is continuously increasing because of environmental and economic factors and as a process for generating valuable products [1].

Polyamide such as nylon is one of the plastics that are widely used in our life. Its depolymerization was explored over 30 years and many efforts have been made so far [2].

The consumption of nylon is small as compared to other polymers. It has high melting point and low solubility, providing nylon with advantageous properties such as thermal, mechanical, and chemical resistance. Thus, nylon is used in extremely broad range of applications and its production and consumption have recently increased.

Nylon recycling has focused on hydrolysis, aminolysis, and pyrolysis. Nylon-6,6 can be depolymerized to corresponding oligomers and monomer [3], while nylon-6 in the presence of phosphoric acid provides a mixture of ethylene glycol derivative and $\varepsilon$-caprolactam and linear oligomers [4].

Duch and Allgeier [5] reported that nylon-6,6 can be recycled via combination of ammonolysis, dehydration, and nitrate hydrogenation in the presence of Raney catalyst to predominantly produce hexamethylenediamine (HMD).

Goto and coworkers [6-8] investigated hydrolysis of nylon- 6 and found aminocaproic acid as first product which underwent cyclodehydration to $\varepsilon$-caprolactam. Their findings were consistent with the depolymerization [9] of nylon6,6 .

Relatively less work has been reported on depolymerization of nylon-6,6. In the present work depolymerization of nylon-6,6 waste by hydrothermal hydrolysis has been investigated. The kinetics of hydrolysis is studied at different temperature by changing concentration of nylon-6,6 waste and hydrochloric acid. The rate constant, energy of activation, Arrhenius constant, enthalpy of activation, entropy of activation, and free energy of activation have also been determined. Based on the kinetic data a mechanistic interpretation of depolymerization of nylon-6,6 work has also been reported. 
TABLE 1: Optimum amount of nylon-6,6 waste.

\begin{tabular}{|c|c|c|c|c|c|}
\hline $\begin{array}{l}\text { Amount of nylon waste } \\
\text { powder/g }\end{array}$ & DBHMD/g & $\mathrm{HMD} / \mathrm{g}$ & $\begin{array}{c}\text { Amount of nylon } \\
\text { waste reacted/g }\end{array}$ & $\begin{array}{c}\text { Amount of unreacted } \\
\text { nylon waste/g }\end{array}$ & $\%$ yield \\
\hline 1 & 0.96 & 0.3437 & 0.6706 & 0.3294 & 67.05 \\
\hline 2 & 1.926 & 0.6896 & 1.3453 & 0.6547 & 67.26 \\
\hline 3 & 3.101 & 1.1102 & 2.1661 & 0.8339 & 72.20 \\
\hline 4 & 2.919 & 1.0451 & 2.0390 & 1.9610 & 50.97 \\
\hline 5 & 2.815 & 1.0078 & 1.9663 & 3.0337 & 39.32 \\
\hline 6 & 2.301 & 0.8238 & 1.6073 & 4.3927 & 26.78 \\
\hline
\end{tabular}

Time of reaction: $120 \mathrm{~min}$.

Temperature: $80^{\circ} \mathrm{C}$.

Concentration of $\mathrm{HCl}: 5 \mathrm{~N}$.

Volume of $\mathrm{HCl}: 50 \mathrm{~mL}$.

The data is useful to design the recycling procedure for nylon waste.

\section{Experimental}

All chemicals used in the present study were of analytical grade. The solutions were prepared by using highly purified deionized double distilled water. $5 \mathrm{~N}$ HCI was obtained by diluting A.R. grade HCI from E. Merck and was standardized with sodium carbonate as well as borax. Nylon waste produced during manufacturing of nylon was obtained from Indorama Polymer Ltd., Butibori, Nagpur, Maharashtra, India. It was chilled to increase brittleness and then crushed, grounded, and sieved into desired particle size of $200 \mu \mathrm{m}$ to increase the surface area for heat and mass transfer in the reaction system.

The viscosity average molecular weight of nylon-6,6 waste powder was determined by using Ostwald's viscometer. Various concentrations $(0.25 \%$ to $2.0 \%)$ of nylon- 6,6 waste dissolved in $m$-cresol were prepared and time of flow was recorded. The intercept of viscosity plotted against concentration was 1.2. The molecular weight was calculated by $\left[\eta_{s p}\right] / C=K M^{\alpha}$ where $K$ and $\alpha$ value for the solvent are $2.4 \times$ $10^{-3}$ and 0.61 , respectively.

The optimum parameters for depolymerization of nylon6,6 waste were determined by gravimetric measurement. Nylon-6,6 waste powder ( $1 \mathrm{~g}$ to $6 \mathrm{~g}$ ) was added to $50 \mathrm{~mL}$ of $5 \mathrm{~N} \mathrm{HCl}$. The reaction mixture was refluxed at $40^{\circ} \mathrm{C}-100^{\circ} \mathrm{C}$ for 30-150 minutes in $0.5 \mathrm{~L}$ three-vertical-neck round bottom flask equipped with a reflux water condenser, microcontroller based stirrer, and internal digital temperature measurement probe. After refluxing for 30-150 minutes, round bottom flask was removed and cooled suddenly. The reaction product was filtered. The filtrate was then neutralized with required volume of $5 \mathrm{~N} \mathrm{NaOH}$ to make it slightly alkaline. It was then treated with benzoyl chloride with vigorous shaking until the odor of acid chloride disappeared. The dissolved HMD gets converted into DBHMD. It was weighed and recrystallised with ethanol. The crystals were grounded to fine powder using mortar and pestle. The melting point of dried and recrystalized DBHMD was determined and found to be $159^{\circ} \mathrm{C}$. The DBHMD was also characterized by recording
FTIR spectra on hyper-IR of Shimadzu make. FTIR spectra of derivative of product (DBHMD) were compared to spectra of standard DBHMD. The optimum parameters determined were further used for kinetic study.

Since the aim of the work is to determine the kinetic and thermodynamic parameters, the temperature stability and its measurement are important. High precision thermostat and digital temperature measurement probe were used in the present work.

Kinetic experiments were carried out at optimum parameters to determine the reaction rate constant. $3 \mathrm{~g}$ nylon- 6,6 waste powder $(200 \mu \mathrm{m})$ and $50 \mathrm{~mL} \mathrm{HCl}(5 \mathrm{~N})$ were added to the reaction flask placed in thermostat. The tip of temperature measurement probe was adjusted so that it is not struck by vertical stirrer bar. The reaction mixture was refluxed at $80^{\circ} \mathrm{C}$; simultaneously stop watch was started. The mixture was refluxed for about 120 minutes. After refluxing, the reaction flask was cooled suddenly and DBHMD was obtained as explained earlier. From the weight of DBHMD, the amounts of nylon-6,6 reacted and unreacted were calculated.

The order of reaction was confirmed by three different methods. Further, the pseudo-first-order reaction rate constant, activation energy, frequency factor (Arrhenius constant), activation entropy, activation enthalpy, and free energy of activation were evaluated.

\section{Results and Discussion}

3.1. Viscosity Average Molecular Weight of Nylon-6,6 Waste Powder. The viscosity average molecular weight was determined by plotting graph of viscosity against concentration. The intercept at ordinate was 1.2. Using the formula $\left[\eta_{s p}\right] / C=$ $K M^{\alpha}$, average molecular weight was calculated where $K$ and $\alpha$ value of the solvent are $2.4 \times 10^{-3}$ and 0.61 , respectively. The average molecular weight of nylon- 6,6 waste powder was 26582.

3.2. Optimization Parameter for Depolymerization of Nylon6,6 Waste. Acid hydrolysis of nylon-6,6 waste was studied using various amounts of nylon- 6,6 waste powder ( $1 \mathrm{~g}$ to $6 \mathrm{~g}$ ) in $50 \mathrm{~mL}$ hydrochloric acid (5 N) (Table 1). Results show an increase in the depolymerization to $99.8 \%$ with increase in 
TABLE 2: Kinetics of depolymerization of nylon-6,6 waste: optimum parameters.

\begin{tabular}{lcc}
\hline S.N. & Parameters & Optimum value \\
\hline 1 & Amount of nylon-6,6 waste powder & $3 \mathrm{~g}$ \\
2 & Reflux time & 120 minutes \\
3 & Concentration of $\mathrm{HCl}$ & $5 \mathrm{~N}$ \\
4 & Volume of $\mathrm{HCl}$ & $50.0 \mathrm{~mL}$ \\
5 & Temperature & $80.0^{\circ} \mathrm{C}$ \\
\hline
\end{tabular}

amount of nylon-6,6 waste powder up to $3 \mathrm{~g}$. Thereafter a sharp decrease is recorded in depolymerization with increase in amount of nylon- 6,6 waste powder. Use of $4 \mathrm{~g}, 5 \mathrm{~g}$, and $6 \mathrm{~g}$ of nylon- 6,6 waste powder shows $73 \%, 56 \%$, and $38 \%$ depolymerization, respectively. Thus $3 \mathrm{~g}$ of nylon- 6,6 waste powder is an optimum amount. Depolymerization was carried out at $3 \mathrm{~g}$ of nylon-6,6, $50 \mathrm{~mL} \mathrm{HCl}(5 \mathrm{~N})$, and temperature of $80^{\circ} \mathrm{C}$ by varying the reflux time from 30 minutes to 150 minutes. It was found that the percentage yield of product increases from $13.71 \%$ to $72.20 \%$ up to 120 minutes. After 120 minutes it decreases to $65.24 \%$ at 150 minutes. It indicates 120 minutes as optimum reflux time (Table 2 ).

The reaction temperature was varied from $40^{\circ} \mathrm{C}$ to $100^{\circ} \mathrm{C}$. It was noticed that the maximum yield of the product was obtained at $80^{\circ} \mathrm{C}$. Above $80^{\circ} \mathrm{C}$ the percentage yield decreases.

Similarly the depolymerization was carried out at various concentrations and volumes of hydrochloric acid. It was found that $5 \mathrm{~N} \mathrm{HCL}$ is the highest concentration for the depolymerization while $50 \mathrm{~mL}$ volume of $\mathrm{HCl}$ is the maximum volume for the depolymerization (Table 2).

3.3. Kinetics of Depolymerization. The kinetics of depolymerization was carried out at optimum parameters. The study was undertaken on the basis of benzoyl derivative of product. From the weight of dibenzoyl derivative of hexamethylenediamine (DBHMD) the amounts of nylon-6,6 reacted and unreacted were evaluated. As for the kinetics of depolymerization of nylon-6,6, it can be treated as a pseudo-first-order reaction. Thus the equation of nylon-6,6 depolymerization kinetics can be expressed as follows:

$$
-\frac{d[\text { nylon-6,6] }}{d t}=k\left[\text { nylon-6,6] }[\mathrm{HCl}]^{m}\left[\mathrm{H}_{2} \mathrm{O}\right]^{n}\right.
$$

due to excess amount of water and $\mathrm{HCl}$, the equation can be simplified as follows:

$$
-\frac{d[\text { nylon-6,6] }}{d t}=k^{\prime}[\text { nylon-6,6] } .
$$

If the initial amount of nylon-6,6 is expressed as [nylon$6,6]_{0}$ and amount at some time interval is expressed as [nylon-6,6] $]_{t}$, then integral of (2) can be written as follows:

$$
\ln \frac{[\text { nylon-6,6] }}{[\text { nylon-6,6] }}=k^{\prime} t \text {. }
$$

As for nylon-6,6 it is solid; thus its amount can be expressed as weight. Therefore, the expression of

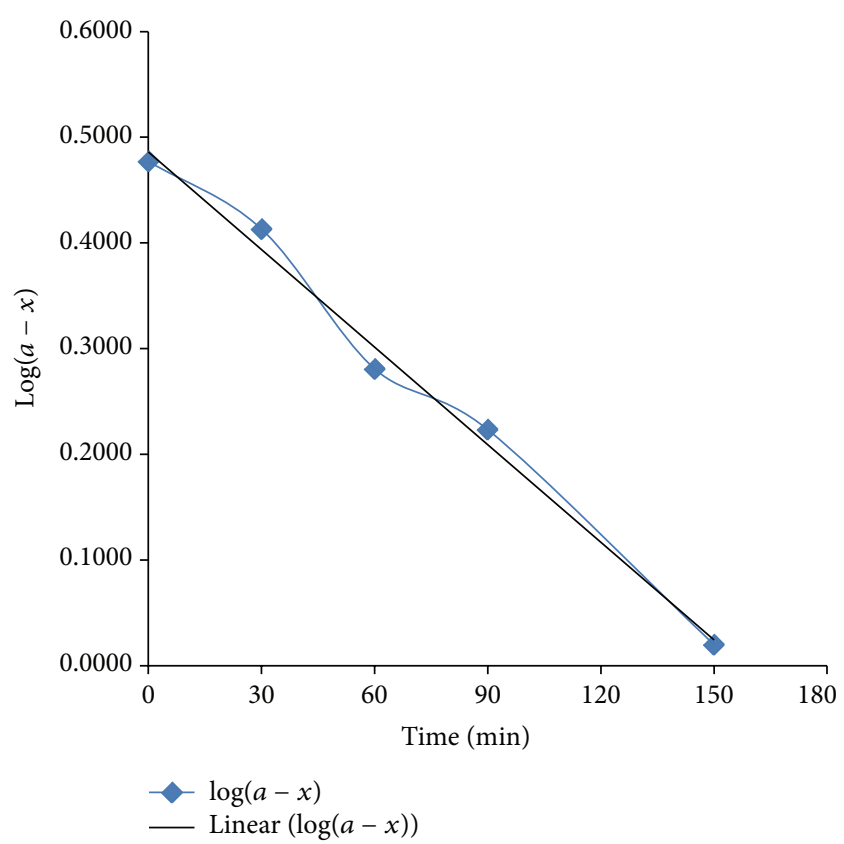

FIGURE 1: Graphical presentation of method 2.

[nylon-6,6 $]_{0} /[\text { nylon-6,6 }]_{t}$ can be expressed as $a /(a-x)$ where $a$ and $a-x$ are initial weight and weight at some time interval, respectively. Thus (3) can be changed as follows:

$$
\ln \frac{a}{a-x}=k^{\prime} t
$$

Figure 1 shows the relation between $\ln (a /(a-x))$ and reaction time. The slope of the plot gives the reaction rate constant of hydrolysis.

The order of reaction was determined by using various methods. The order of reaction was determined by performing the depolymerization of nylon waste reaction at optimum conditions set previously. The reaction was carried out by altering the amount of reactant, that is, nylon waste. The amount of the product dibenzoyl derivative of hexamethylenediamine (DBHMD) was determined at particular time interval. The data is tabulated. It is observed that if the differences in the consecutive values of concentration of initial concentration $[A]$ of reactant are similar then the reaction follows zero-order kinetics. If the differences in the consecutive values of $\ln [A]$ are similar then reaction is of first-order nature. On the other hand, if the differences in the consecutive values of $1 /[A]$ are similar then reaction is a second-order reaction. Data shown in Table 3 indicate the similarities between the consecutive values of $\ln [A\}$; this proves the first-order nature of reaction [10] (Table 3).

The rate equation for the first-order reaction is $K=$ $(2.303 / t) \log (a /(a-x))$; if this equation is rearranged as $\log (a-x)=-K t / 2.303+\log a$, it is an equation of type $y=m x+c$. When the graph was plotted between $\log (a-x)$ and time in minute a straight line of negative slope is obtained which proves the first-order nature of reaction [11] (Table 4 and Figure 1). 
TABLE 3: Order of depolymerization of nylon-6,6 waste (method 1).

\begin{tabular}{lcccccccc}
\hline $\begin{array}{l}\text { Heating } \\
\text { time }\end{array}$ & DBHMD/g & $\begin{array}{c}\text { Amount of reacted } \\
\text { nylon waste/g }\end{array}$ & $\begin{array}{c}\text { Amount of } \\
\text { unreacted nylon } \\
\text { waste/g }[A]\end{array}$ & $\begin{array}{c}\text { Difference in } \\
\text { successive }[A]\end{array}$ & $\begin{array}{l}\ln [A] \\
\text { successive } \ln [A]\end{array}$ & $\begin{array}{c}\text { Difference in }[A] \\
\text { Difference in } \\
\text { successive } 1 /[A]\end{array}$ \\
\hline $0 \mathrm{~min}$ & - & - & 3 & 0.4114 & 1.0986 & 0.1475 & 0.33 & -0.56 \\
$30 \mathrm{~min}$ & 0.589 & 0.4114 & 2.5886 & 0.679 & 0.9511 & 0.2946 & 0.386 & -0.138 \\
$60 \mathrm{~min}$ & 1.562 & 1.0911 & 1.9089 & 0.2368 & 0.6465 & 0.1325 & 0.524 & -0.74 \\
$90 \mathrm{~min}$ & 1.901 & 1.3279 & 1.6721 & 0.8382 & 0.5141 & 0.6957 & 0.598 & -0.601 \\
$120 \mathrm{~min}$ & 3.101 & 2.1661 & 0.8339 & -0.2089 & 0.1816 & 0.1397 & 1.199 & 0.24 \\
$150 \mathrm{~min}$ & 2.802 & 1.9572 & 1.0428 & 0 th order & 0.0419 & 1 1st order & 0.959 & $2 \mathrm{nd}$ order \\
\hline
\end{tabular}

TABLE 4: Order of depolymerization of nylon-6,6 waste (method 2).

\begin{tabular}{lcc}
\hline Time/min & $(a-x)$ & $\log (a-x)$ \\
\hline 0 & $a=3$ & 0.4771 \\
30 & 2.5886 & 0.4131 \\
60 & 1.9089 & 0.2808 \\
90 & 1.6721 & 0.2233 \\
120 & 0.8339 & -0.0788 \\
150 & 1.0468 & 0.0199 \\
\hline
\end{tabular}

a: initial concentration of nylon-6,6 waste.

TABLE 5: Order of depolymerization of nylon-6,6 waste (method 3).

\begin{tabular}{lccc}
\hline Time $/$ min & $a-x$ & $a /(a-x)$ & $\log (a / a-x)$ \\
\hline 0 & $a=3$ & 1 & 0 \\
30 & 2.5886 & 1.1589 & 0.0641 \\
60 & 1.9089 & 1.5716 & 0.1963 \\
90 & 1.6721 & 1.7942 & 0.2539 \\
120 & 0.8339 & 3.5975 & 0.5560 \\
150 & 1.0468 & 2.8659 & 0.4573 \\
\hline
\end{tabular}

Similarly when the above equation is rearranged as $\log (a /(a-x))=K t / 2.303$, it is an equation of type $y=$ $m x$. Therefore when the graph is plotted between $\log (a /(a-$ $x)$ ) and time in minute, a straight line passing through origin is obtained. This confirms the first-order nature of depolymerization of nylon waste reaction [11] (Table 5 and Figure 2).

The amount of hydrochloric acid used was in large excess and its concentration was not altered by significant value. Thus the reaction is a pseudo-first-order reaction.

On the basis of our result this depolymerization is a firstorder reaction with respect to nylon-6,6 concentration, as the concentration of $\mathrm{HCl}$ is high and does not change appreciably during the course of reaction. The reaction rate constant recorded is $7.32 \times 10^{-3} \mathrm{~min}^{-1}$ at $80^{\circ} \mathrm{C}$.

The straight line in the graph of $\log (a /(a-x))$ versus time in minutes which almost passes through origin and slope gives the value of reaction rate constant $7.32 \times 10^{-3} \mathrm{~min}^{-1}$ and shows pseudo-first-order reaction kinetics (Figure 2). The reaction rate constant was evaluated by carrying out depolymerization at various temperatures, that is, $40^{\circ} \mathrm{C}$ to $100^{\circ} \mathrm{C}$ (Table 6).

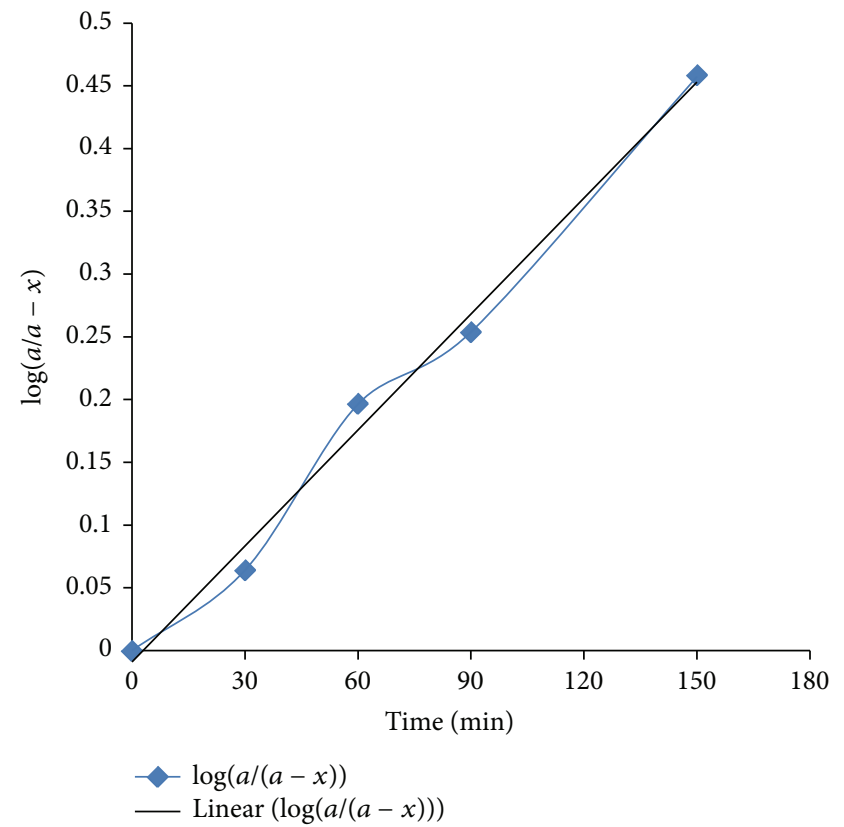

FIgURE 2: Graphical presentation of method 3.

On increasing the reaction temperature up to $80^{\circ} \mathrm{C}$, the rate constant of the reaction increases up to $7.32 \times 10^{-3} \mathrm{~min}^{-1}$. After $80^{\circ} \mathrm{C}$ the rate constant decreases to $7.09 \times 10^{-3} \mathrm{~min}^{-1}$ at $100^{\circ} \mathrm{C}$. Thus the optimum condition obtained at $80^{\circ} \mathrm{C}$ for the rate constant of the reaction. Above this temperature, the decrease in rate constant is due to the decrease in nylon-6,6 concentration and generated HMDA tends to adhere to the surface of nylon- 6,6 particles.

3.4. Thermodynamics of Hydrolytic Depolymerization of $\mathrm{Nyl}$ on-6,6 Waste. The reaction rate constants for depolymerization of nylon-6,6 waste were determined at temperature ranging from $40^{\circ} \mathrm{C}$ to $100^{\circ} \mathrm{C}$. The Arrhenius equation used to evaluate activation energy is $k=A \cdot e^{-E a / R T}$ where $k$ is rate constant of the depolymerization, $A$ is Arrhenius constant, $R$ is gas constant, and $T$ is the temperature in Kelvin. Taking natural logarithm on both sides of Arrhenius equation,

$$
\ln k=-\frac{E a}{R T}+\ln A
$$


TABLE 6: Effect of temperature on rate constant of depolymerization reaction.

\begin{tabular}{lcccrr}
\hline S.N. & \multicolumn{2}{c}{ Temperature/T } & Rate constant $/ k \times 10^{-3}, \mathrm{~min}^{-1}$ & $1 / T \times 10^{-3} / \mathrm{K}^{-1}$ \\
\hline 1 & ${ }^{\circ} \mathrm{C}$ & $\mathrm{K}$ & 4.298 & 3.2 & -5.45 \\
2 & 40 & 313 & 5.127 & 3.1 & -5.27 \\
3 & 50 & 323 & 5.914 & 3.0 & -5.13 \\
4 & 60 & 333 & 6.615 & 2.9 & -5.02 \\
5 & 70 & 353 & 7.320 & -4.92 \\
6 & 80 & 373 & 7.098 & -4.9 \\
\hline
\end{tabular}

TABLE 7: Thermodynamic parameter for depolymerization.

\begin{tabular}{|c|c|c|c|c|c|}
\hline Temperature in $\mathrm{K}$ & Rate constant $/ k \times 10^{-3}, \mathrm{~min}^{-1}$ & $1 / T \times 10^{-3} / \mathrm{K}^{-1}$ & $\ln k$ & $\begin{array}{l}k / T \\
10^{-05}\end{array}$ & $\ln (k / T)$ \\
\hline 313 & 4.298 & 3.2 & -5.45 & 1.37316 & -11.1958 \\
\hline 323 & 5.127 & 3.1 & -5.27 & 1.58731 & -11.0509 \\
\hline 333 & 5.914 & 3.0 & -5.13 & 1.77598 & -10.9386 \\
\hline 343 & 6.615 & 2.9 & -5.02 & 1.92857 & -10.8561 \\
\hline 353 & 7.32 & 2.8 & -4.92 & 2.07365 & -10.7836 \\
\hline 373 & 7.098 & 2.7 & -4.95 & 1.90295 & -10.8695 \\
\hline
\end{tabular}

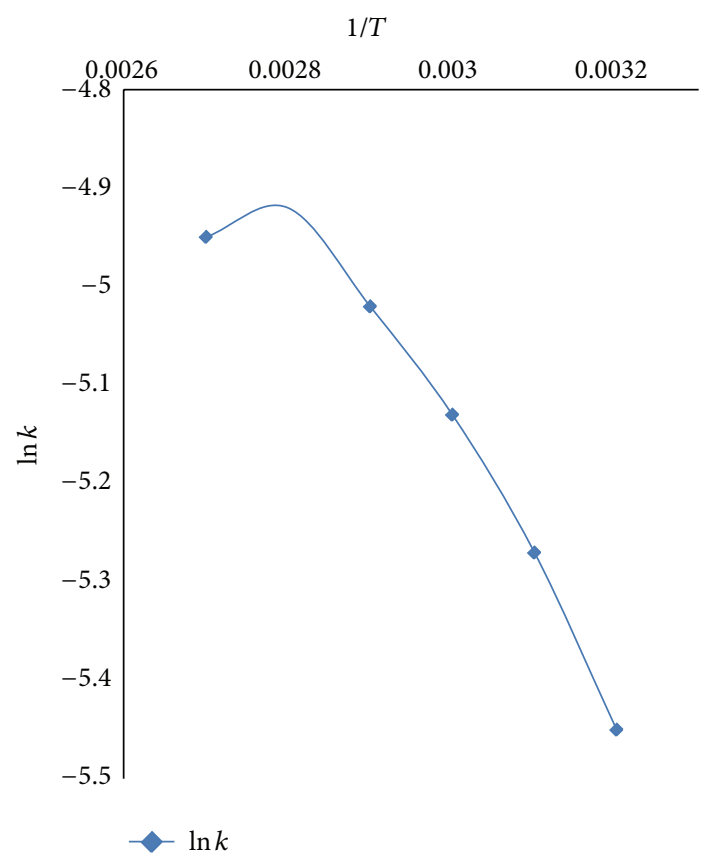

FIGURE 3: Activation energy for depolymerization.

The equation can be converted to

$$
\log k=-\frac{E a}{2.303 R T}+\log A .
$$

This is the equation of the straight line. The Arrhenius plot can be drawn using the values of $\log k$ versus $1 / T$. The activation energy obtained from the slope is $87.22 \mathrm{KJg}^{-1}$ (Table 6 and Figure 3). The intercept of the plot is -2.0437 units, which is used to obtain Arrhenius constant of $0.129 \mathrm{~min}^{-1}$.
The thermodynamic parameters such as activation entropy and activation enthalpy were evaluated using the general form of Eyring-Polanyi equation [12]:

$$
k=\frac{k_{b} T}{h} \times e^{\Delta G^{\ddagger} / R T},
$$

where $k$ is rate constant of depolymerization, $k_{b}$ is the Boltzmann constant, $T$ is the temperature in Kelvin, $h$ is the planks constant, $\Delta G^{\ddagger}$ is the free energy of activation, and $R$ is the gas constant. As $-\Delta G^{\ddagger}=-\Delta H^{\ddagger}+T \Delta S^{\ddagger}$, by substituting and rearranging, the equation can be converted into straight line equation as follows:

$$
\ln \frac{k}{T}=\frac{\Delta H^{\ddagger}}{R} \times \frac{1}{T}+\ln \frac{k_{b}}{h}+\frac{\Delta S^{\ddagger}}{R} ;
$$

plotting the graph of $\ln (k / T)$ versus $1 / T$ gives the straight line with slope $\Delta H^{\ddagger} / R$ and intercept $\ln \left(k_{b} / h\right)+\Delta S^{\ddagger} / R$, from which $\Delta S^{\ddagger}$ and $\Delta H^{\ddagger}$ can be evaluated. The activation entropy and activation enthalpy obtained are $-270.86 \mathrm{JK}^{-1}$ mole and 5975.85 J, respectively (Table 7 and Figure 4). The value of free energy of activation is determined by using the equation $\Delta G^{\ddagger}=\Delta H^{\ddagger}-T \Delta S^{\ddagger}$ at $80^{\circ} \mathrm{C}$ and found to be $101.59 \mathrm{KJ} \cdot \mathrm{mol}^{-1}$.

The FTIR spectra of control DBHMDA and DBHMDA obtained by depolymerization of nylon-6,6 waste were recorded; the spectra are identical as shown in Figures 5 and 6. The various peaks obtained in FTIR of experimental product are shown in Figure 6.

All bands (peaks) that appeared are sharp which rules out the presence of any sort of hydrogen bonding. Characteristics of strong band between $3082 \mathrm{~cm}^{-1}$ and $2500 \mathrm{~cm}^{-1}$ indicate carbon-hydrogen containing species and are assigned to various forms of $\mathrm{C}-\mathrm{H}$ stretching. Some complex band above $3100 \mathrm{~cm}^{-1}$ is indicating the presence of unsaturation in 


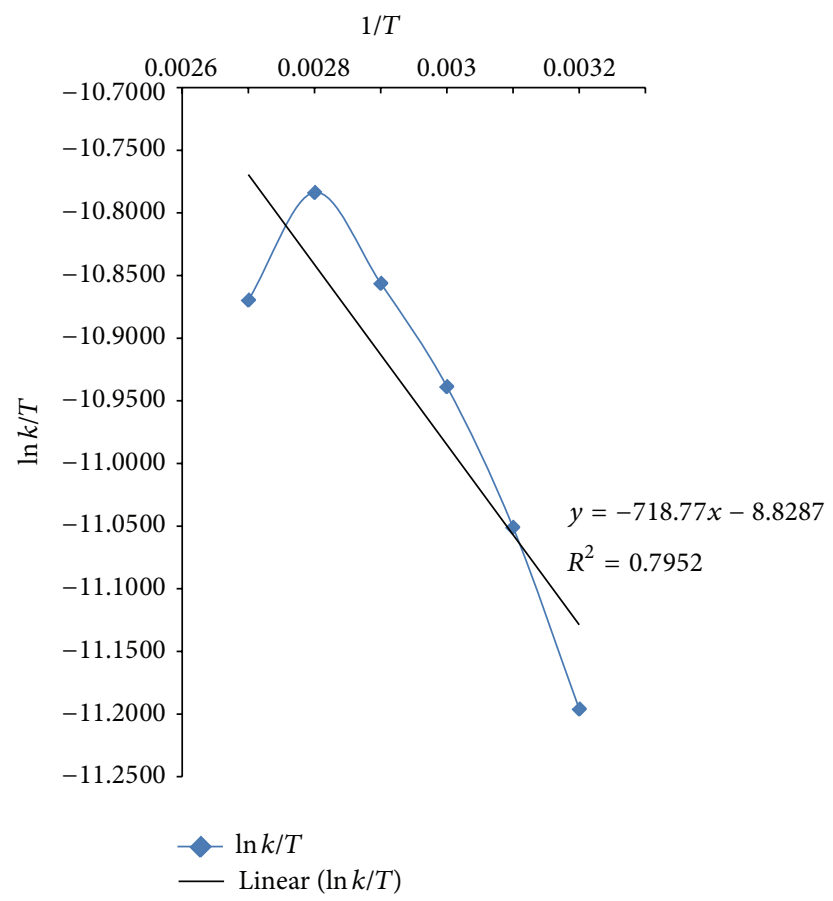

FIgURE 4: Determination of thermodynamic parameters.

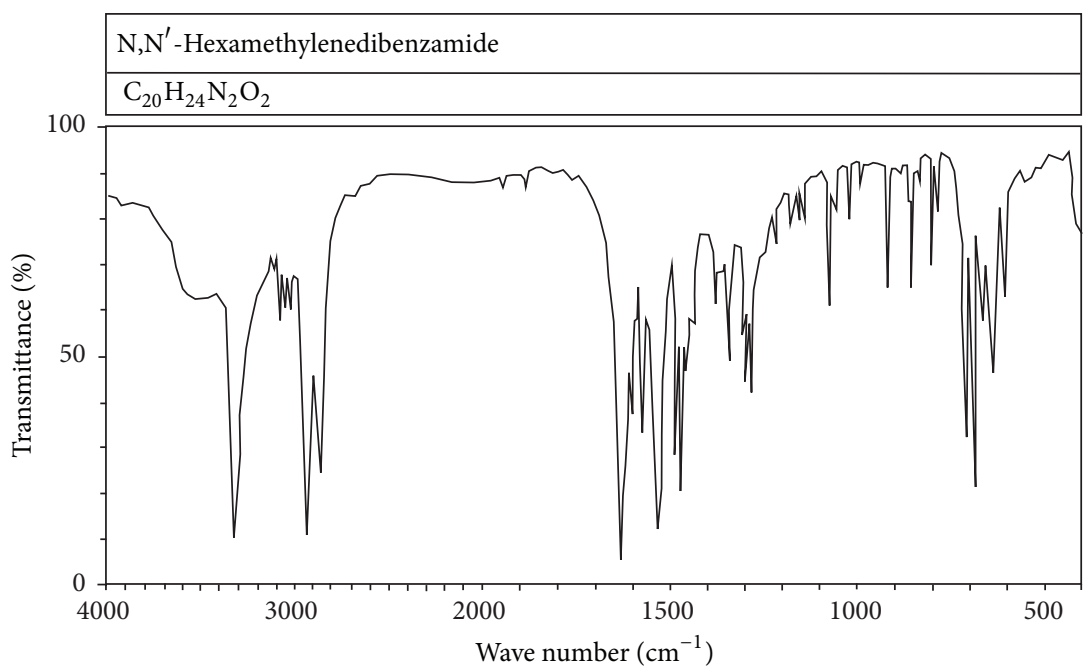

\begin{tabular}{lllllllllll}
\hline 3321 & 9 & 2966 & 26 & 1606 & 35 & 1378 & 68 & 861 & 62 \\
3127 & 66 & 2936 & 10 & 1578 & 32 & 1345 & 47 & 806 & 68 \\
3104 & 66 & 2919 & 17 & 1556 & 11 & 1507 & 55 & 716 & 30 \\
3083 & 65 & 2870 & 24 & 1489 & 26 & 1301 & 42 & 691 & 20 & $\mathrm{O}$ \\
3058 & 58 & 2859 & 23 & 1478 & 19 & 1290 & 39 & 672 & 55 & \\
3044 & 62 & 1628 & 4 & 1462 & 44 & 1079 & 50 & 647 & 43 & \\
3031 & 68 & 1618 & 28 & 1440 & 65 & 924 & 62 & 616 & 60 & \\
\hline
\end{tabular}

FIGURE 5: FTIR spectra of controlled DBHMD.

aromatic structure. There are absorption bands both between $2935 \mathrm{~cm}^{-1}$ and $2860 \mathrm{~cm}^{-1}$ and at $1470 \mathrm{~cm}^{-1}$ to $720 \mathrm{~cm}^{-1}$ indicating the presence of long chain of aliphatic methylene group. The large number of peaks between $1500 \mathrm{~cm}^{-1}$ and $400 \mathrm{~cm}^{-1}$ is regarded as fingerprint region due to different type of vibrations that occurs in molecule; these include single bond stretch and wide variety of vibrations. The strong and sharp band at the left hand of the spectrum is in the range between $3100 \mathrm{~cm}^{-1}$ and $3500 \mathrm{~cm}^{-1}\left(3318 \mathrm{~cm}^{-1}\right.$ in this spectrum) for $\mathrm{N}-\mathrm{H}$ stretch in amide functional group 


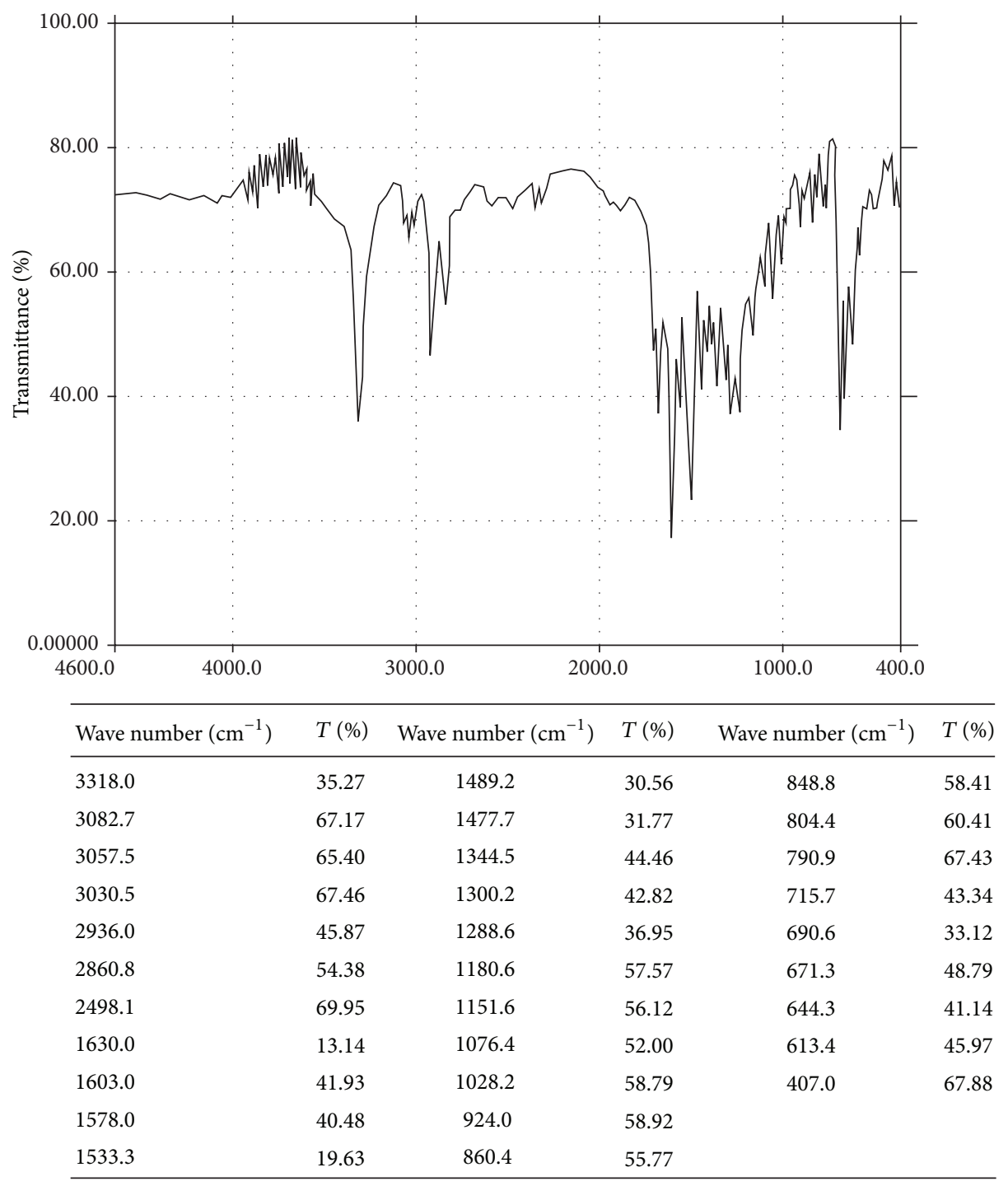

FigURE 6: FTIR spectra of DBHMD (product).

because it shows the combined feature of amine and ketone as it has both $\mathrm{N}-\mathrm{H}$ bond and $\mathrm{C}=\mathrm{O}$ bond. At the same time spectrum does not show stake shaped band in the middle of the spectrum around $1700 \mathrm{~cm}^{-1}$ to $1740 \mathrm{~cm}^{-1}$ for the $\mathrm{C}=\mathrm{O}$ stretch indicating its absence; whereas due to its association with $\mathrm{N}-\mathrm{H}$ in amide group it gives sharp peak at $1630 \mathrm{~cm}^{-1}$, this band is one of the prominent band in the spectrum. Similarly no band in the region $1750 \mathrm{~cm}^{-1}$ to $2400 \mathrm{~cm}^{-1}$ indicates the absence of multiple bonded $\mathrm{N}$ as in nitrile, cyanate, diazo, and so forth. Similar spectrum is obtained for controlled product; hence similar explanation is applicable.

\section{Conflict of Interests}

The authors declare that there is no conflict of interests regarding the publication of this paper.

\section{References}

[1] Research Association of Feedstock Recycling of Plastics, Technology for Feedstock Recycling of Plastic Wastes, CMC Books, Tokoyo, Japan, 2005.

[2] S. R. Shukla, A. M. Harad, and D. Mahato, "Depolymerization of nylon 6 waste fibers," Journal of Applied Polymer Science, vol. 100, no. 1, pp. 186-190, 2006.

[3] M. B. Polk, L. L. Leboeuf, M. Shah, W. Chee-Youb, X. Hu, and W. Ding, "Nylon 66, nylon 46, and pet phase-transfer-catalyzed alkaline depolymerization at atmospheric pressure," PolymerPlastics Technology and Engineering, vol. 38, no. 3, pp. 459-470, 1999.

[4] B. Hommez and E. J. Goethals, "Degradation of nylon- 6 by glycolysis. Part 1: identification of degradation products," Journal of Macromolecular Science-Pure and Applied Chemistry, vol. 35, no. 9, pp. 1489-1505, 1998. 
[5] M. W. Duch and A. M. Allgeier, "Deactivation of nitrile hydrogenation catalysts: new mechanistic insight from a nylon recycle process," Applied Catalysis A: General, vol. 318, pp. 190198, 2007.

[6] M. Goto, M. Umeda, A. Kodama, T. Hirose, and S. Nagaoka, "Monomerization of nylon 6 in sub-and supercritical water," Kobunshi Ronbunshu, vol. 58, no. 10, pp. 548-551, 2001.

[7] M. Goto, M. Umeda, A. Kodama, T. Hirose, S. Magaoka, and S. Matusla, "Synthesis of 2-amino- $\varepsilon$-caprolactam by cyclodehydration of lysine in subcritical water," Journal of Chemical Engineering of Japan, vol. 37, p. 353, 2004.

[8] T. Iwaya, M. Sasaki, and M. Goto, "Kinetic analysis for hydrothermal depolymerization of nylon 6," Polymer Degradation and Stability, vol. 91, no. 9, pp. 1989-1995, 2006.

[9] L. Meng, Y. Zhang, Y. Huang, M. Shibata, and R. Yosomiya, "Studies on the decomposition behavior of nylon-66 in supercritical water," Polymer Degradation and Stability, vol. 83, no. 3, pp. 389-393, 2004.

[10] K. J. Laidler, Chemical Kinetics, Pearson Education, Singapore, 2004.

[11] J. C. Kuriacose and J. Rajaram, Kinetics and Mechanisms of Chemical Transformations, Macmillan, 2009.

[12] B. R. Puri, L. R. Sharma, and M. S. Pathania, Principles of Physical Chemistry, Vishal Publishing, Jalandhar, India, 2005. 

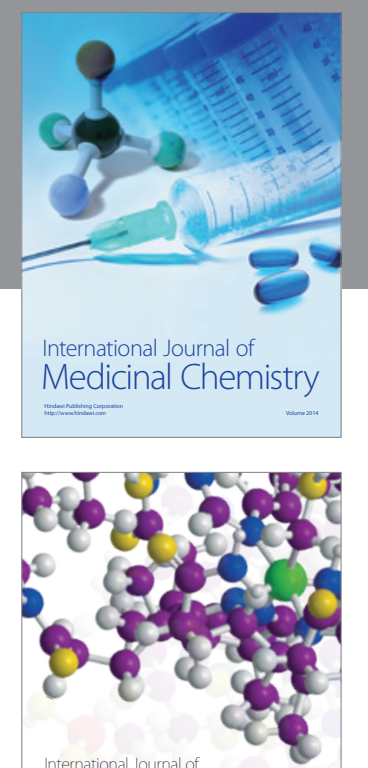

\section{Carbohydrate} Chemistry

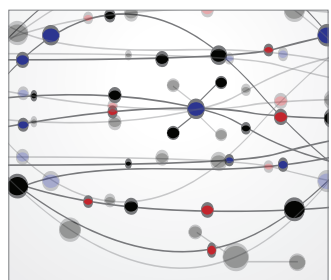

The Scientific World Journal
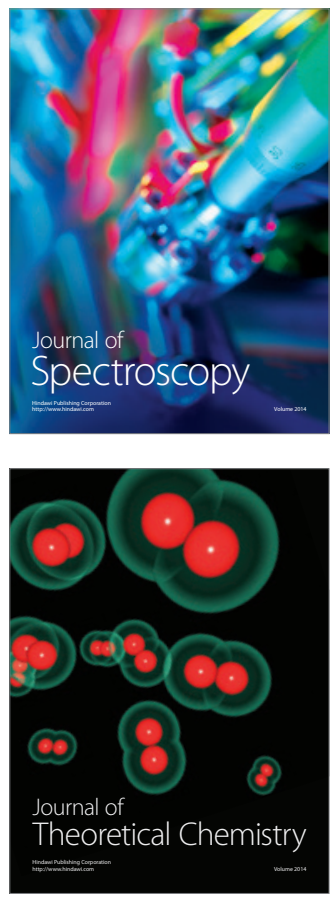
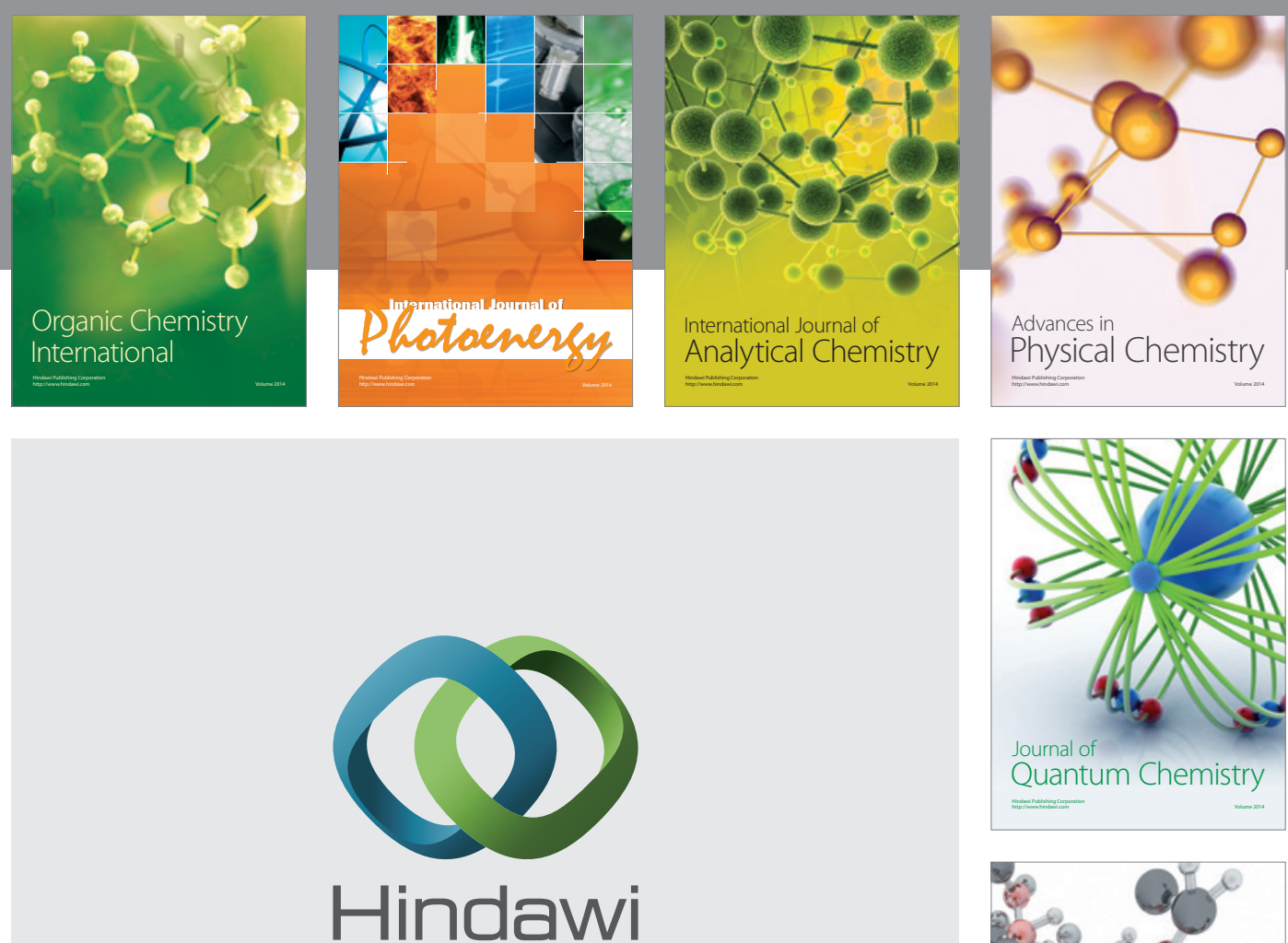

Submit your manuscripts at

http://www.hindawi.com

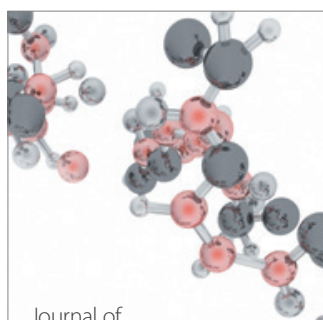

Analytical Methods

in Chemistry

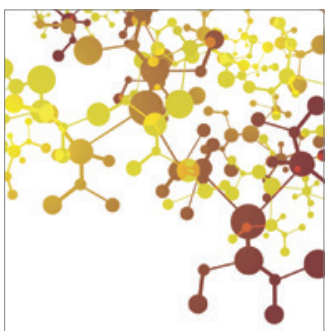

Journal of

Applied Chemistry

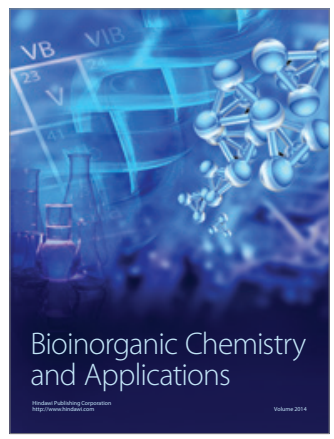

Inorganic Chemistry
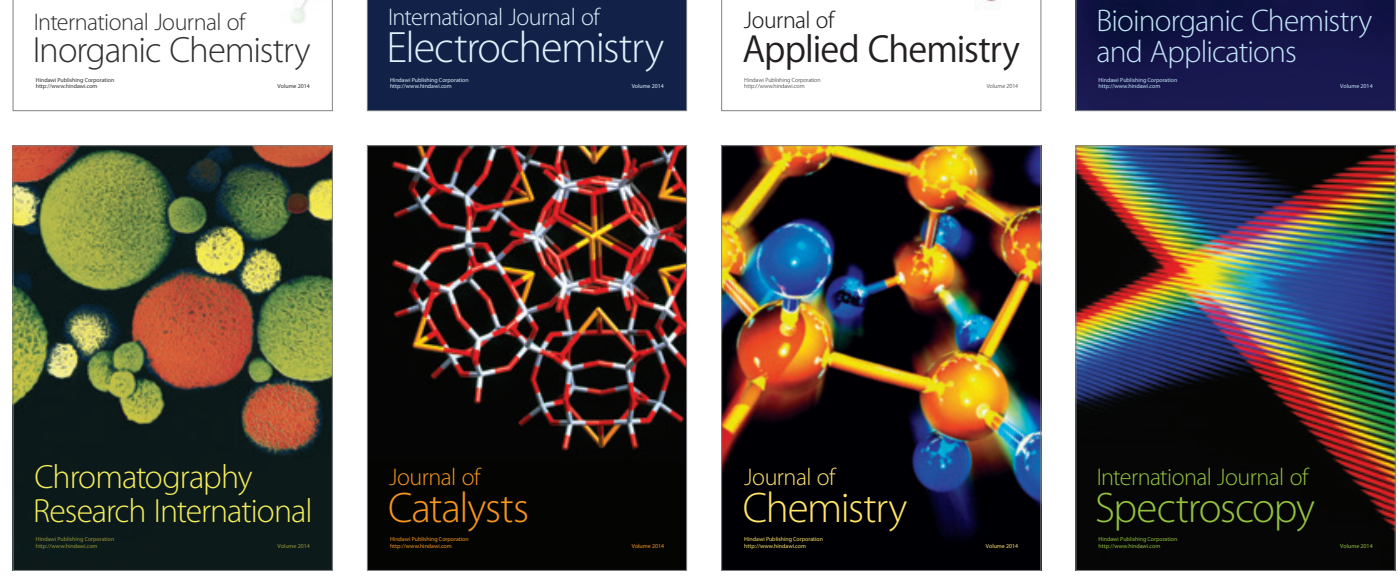